\title{
EFFECT OF ORGANIC SOIL ON STRENGTH PROPERTIES OF COMPRESSED CEMENT-SOIL BLOCK
}

\author{
M. S. Shirin ${ }^{1}$, M. M. Ali ${ }^{2}$, M. R. Hasan ${ }^{3}$ and Md. Saiful Islam ${ }^{4}$ \\ 1,2,3 Department of Civil Engineering, Bangladesh Army University of Engineering \& Technology, Qadirabad Cantonment, \\ Natore-6431, Bangladesh \\ ${ }^{4}$ Department of Chemistry, Bangladesh Army University of Engineering \& Technology, Qadirabad Cantonment, Natore- \\ 6431, Bangladesh.
}

Corresponding author's email: shamima091@yahoo.com

\begin{abstract}
Compressed cement-soil block is used as low cost building material. In the south-western region of Bangladesh, there is availability of organic soil which is in the formation of overlying layer. Moreover, sandy materials do not occur and are not found easily in Bangladesh. The scarcity of sandy materials has led to the increase of the retail price and subsequently to higher production cost. So organic soil materials have been used as filler directly to produce cement-soil block. In this study, the compressive and flexural strengths of cement-soil block of density $1448 \mathrm{~kg} / \mathrm{m}^{3}$ to $1611 \mathrm{~kg} / \mathrm{m}^{3} \mathrm{with}$ specified ratio of cement content were investigated using prism specimens. The observed elapsed periods were 1, 3, 7, 14, 28,56 and 112 days with the variation of organic contents of $2 \%, 5 \%, 10 \%, 20 \%$ and $40 \%$. Preferable results on the $28^{\text {th }}$ day indicated that the compressive strength and the flexural strength of cement-soil block with $20 \%$ organic content increased by $125 \%$ and $102 \%$ respectively. Moreover, the influence of density on the strength properties of cement-soil block was found to be higher than the age of the specimen.
\end{abstract}

Keywords: Organic soil, cement-soil block, compressive strength, flexural strength, dry density

\subsection{INTRODUCTION}

Soil is a result of the influence of climate, relief (elevation, orientation, and slope of terrain), organisms, and parent materials interacting over time [1,5]. Soil repeatedly undergoes maturity by way of numerous physical, chemical and biological processes, which comprise weathering with associated erosion. Soils are generally weak in tension. The tensile strength of soil is very low or negligible and in most analyses it is considered to be zero. Soil abrasion resistance is very stumpy. Soil absorbs water in high range and has a high capacity of retention. At the time of cyclic drying and wetting it is dimensionally instable [1].

To measure the workability of cement-soil mixture various researches have been done since 1950's [2, $13,17]$. To make cement-soil blocks, first soil is compressed, then it is mixed with binding material cement and a suitable amount of water. At the time of mixing cork sheet is added to lessen the weight. The purpose of this study is to produce cement-soil block which can be used as a low cost building material in the urban construction of some developing countries $[12,16]$. Soil properties, amount of cement, soil compaction technique and water quality are the main factors affecting cement-soil block.

Any soil containing a considerable quantity of organic matter to influence its engineering properties is called an organic soil. Organic soils are formed by decay of plants and animals. Accumulations of organic materials may be found in association with almost any type of geological deposit when the environmental conditions are appropriate. The properties of each soil layer depend on various factors. Weather, ground slope and the amount of organic matter are factors which change the soil layers [5]. 
Organic accumulations such as peat, muck, muskeg and marsh deposits may vary in thickness from a few inches to several feet.

At the south-western region of Bangladesh, there is an available overlying layer of organic soil so it is used as a base for the manufacture of cement-soil block. Much research has been carried out on cement-soil block, however so far none on the effect of organic soil on cement-soil block using Teligati and KUET campus soil in Bangladesh. Thus, the purpose of this study is to observe the effect of various organic contents on the strength properties of cement-soil block.

\subsection{MATERIALS}

\subsection{SOIL}

In this research, five types of soils were used. In Bangladesh, the organic soil layer exists in most places within a depth of 10 to $25 \mathrm{ft}$ below the surface. Soil was collected at a depth of $4 \mathrm{ft}$ near the Teligati and at a depth of $7 \mathrm{ft}$ inside the KUET campus, Bangladesh. Impurities such as tree roots, grass and leaves were removed. After that the soils were smashed to pass $40 \mathrm{~mm}$ sieve in the laboratory. Sufficient soil samples were taken to the laboratory for tests. Then the physical properties of the soil samples were determined as shown in Table 1.

Table 1 Physical properties of organic soil

\begin{tabular}{ccccc}
\hline \multirow{2}{*}{ Organic Content (\%) } & $\begin{array}{c}\text { Specific Gravity, } \\
\text { Gs }\end{array}$ & $\mathrm{W}_{\mathrm{L}}(\%)$ & $\mathrm{W}_{\mathrm{P}}(\%)$ & $\mathrm{I}_{\mathrm{P}}(\%)$ \\
\hline 2 & 2.03 & 35 & 18 & 17 \\
5 & 2.23 & 43 & 24 & 19 \\
10 & 2.46 & 50 & 38 & 12 \\
20 & 2.52 & 77 & 42 & 35 \\
40 & 2.27 & 330 & 270 & 60 \\
\hline
\end{tabular}

\subsection{BINDING MATERIAL}

Many suitable binders could potentially be used for compressed cement-soil blocks. In this research, Ordinary Portland Cement (OPC) was used. The chemical and physical composition of OPC is presented in Table 2 and Table 3.

Table 2 Chemical composition of OPC

\begin{tabular}{lll}
\hline Constituents & Oxide Composition & Percent Composition \\
\hline Tricalcium silicate & $3 \mathrm{CaO} . \mathrm{SiO}$ & $45-55$ \\
Dicalcium silicate & $2 \mathrm{CaO} \cdot \mathrm{SiO}_{2}$ & $20-30$ \\
Ticalcium aluminate & $3 \mathrm{CaO} \cdot \mathrm{Al}_{2} \mathrm{O}_{3}$ & $9-13$ \\
Tetracalcium aluminoferrite & $4 \mathrm{CaO}_{2} \mathrm{Al}_{2} \mathrm{O}_{3} \mathrm{Fe}_{2} \mathrm{O}_{3}$ & $8-20$ \\
Calcium sulphate & $\mathrm{CaSO}_{4}$ & $2-6$ \\
Other compounds & - & $2-8$ \\
\hline
\end{tabular}




\section{Journal of Civil Engineering, Science and Technology}

Volume 8, Issue 1, April 2017

Table 3 Physical composition of OPC

\begin{tabular}{lcc}
\hline Property & Unit & Value \\
\hline Specific surface & $\mathrm{cm}^{2} / \mathrm{gm}$ & 2250 \\
Initial setting time & minute & 30 \\
Final setting time & minute & 600 \\
Crushing strength at 3 days & $\mathrm{N} / \mathrm{mm}^{2}$ & 16 \\
Crushing strength at 7 days & $\mathrm{N} / \mathrm{mm}^{2}$ & 22 \\
\hline
\end{tabular}

\subsection{WATER}

In this research, distilled water was used throughout the test using the ratio water : binder -0.45 .

\subsection{FOAMING AGENT}

Cork sheet was used as a foaming agent in this study.

\subsection{METHODOLOGY}

\subsection{ORGANIC CONTENT}

To determine organic content, loss on ignition method was used, as shown in Equation 1.

Where,

$$
\text { Organic content }=(\mathrm{A}-\mathrm{B}) /(\mathrm{A}-\mathrm{C}) * 100
$$

$\mathrm{A}=$ Weight of crucible or evaporation dish and oven dry soil, before ignition.

$\mathrm{B}=$ Weight of crucible or evaporation dish and oven dry soil, after ignition at a temperature of $450^{\circ} \mathrm{C}$ to $500^{\circ} \mathrm{C}$ for six hours.

$\mathrm{C}=$ Weight of crucible or evaporation dish, to the nearest $0.01 \mathrm{gm}$.

\subsection{SPECIFIC GRAVITY}

The specific gravity is the ratio of unit weight of solid to the unit weight of water. The specific gravity was measured by Equation 2.

$$
\mathrm{G}_{\mathrm{s}}=\gamma_{\mathrm{s}} / \gamma_{\mathrm{w}}
$$

The value of specific gravity for most natural soil falls in the general range of 2.65 to 2.75 .

\subsection{MOISTURE CONTENT}

The oven-drying method was used to determine the moisture contents of the samples. Small representative specimens obtained from large bulk samples were weighed as received, then oven-dried at $105^{\circ} \mathrm{C}$ for 24 hours. The sample was then weighed. The difference in weight was assumed to be the weight of water driven off during drying. The difference in weight was divided by the weight of the dry soil, giving the water content on a dry weight basis. 


\section{Journal of Civil Engineering, Science and Technology}

Volume 8, Issue 1, April 2017

\subsection{ATTERBERG LIMIT TEST}

\subsubsection{LIQUID LIMIT $\left(\mathrm{W}_{\mathrm{L}}\right)$}

It is defined as the moisture content in percentage at which the soil changes from the liquid test.

\subsubsection{PLASTIC LIMIT $\left(\mathrm{W}_{\mathrm{P}}\right)$}

It is defined as the moisture content in percentage at which the soil changes from a plastic state to semisolid state.

\subsubsection{PLASTICITY INDEX (PI/ I $)$}

It is defined as the difference between liquid limit and plastic limit as shown in Equation 3.

$$
\mathrm{I}_{\mathrm{P}}=\mathrm{W}_{\mathrm{L}}-\mathrm{W}_{\mathrm{P}}
$$

\subsection{DENSITY}

The density is the ratio of mass of the soil sample to the volume of sample which was shown in Equation 4.

$$
\rho=M / V
$$

Where,

M=mass of soil sample

$\mathrm{V}=$ volume of soil sample

\subsection{COMPRESSIVE STRENGTH}

The compressive strength is the capacity of a material or structure to withstand loads tending to reduce size (Figure 1). When specimen of material is loaded in such a way that it shortens then it is said to be in compression. Some materials crack at their compressive strength limit while others warp irreversibly, so a given quantity of deformation may be considered at the limit for compressive load. Compressive strength is a key value for designing structures.

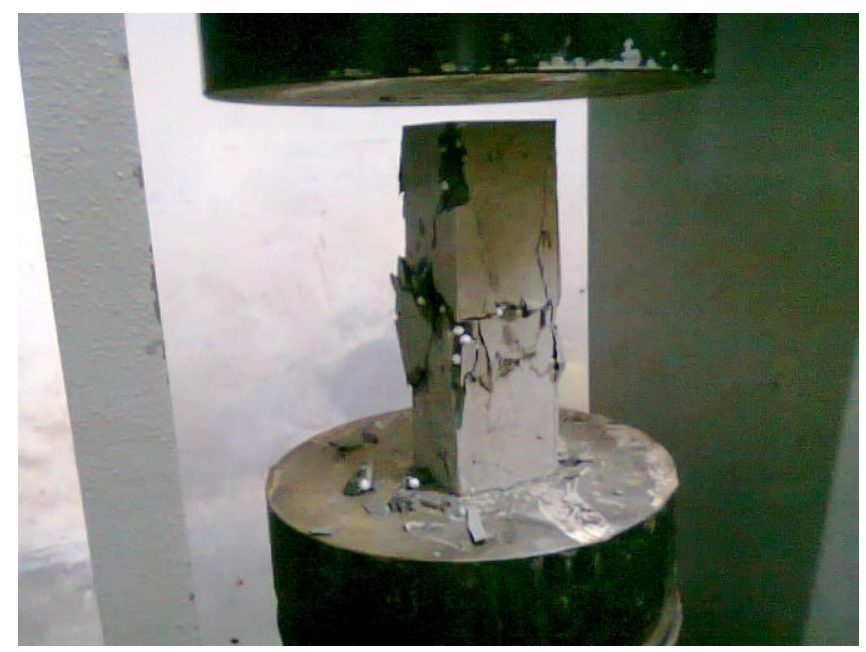

Figure 1 Compressive Strength Test of Cement-Soil Block 


\section{Journal of Civil Engineering, Science and Technology}

Volume 8, Issue 1, April 2017

\subsection{FLEXURAL STRENGTH}

Flexural strength is defined as a material ability to resist deformation under load. This strength is measured by centre-point loading method. In this method, the soil prism is provided as simply supported frame which is supported at the two ends and a point load is performed at the mid span (Figure 2). This loading condition is the procedure to determine the flexural strength.

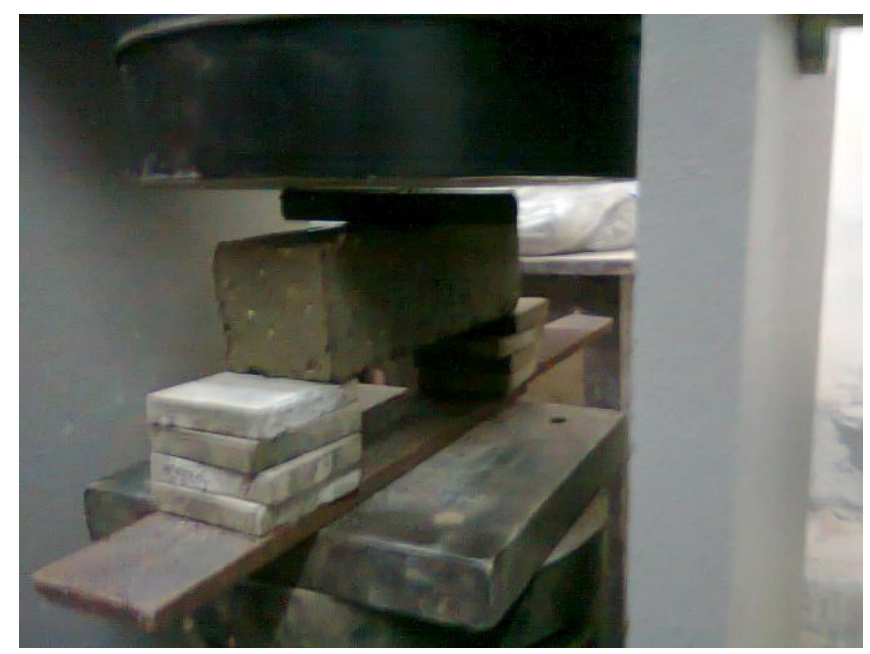

Figure 2 Flexural Strength Test of Cement-Soil Block

\subsection{PREPARATION AND CASTING}

Each of the five soil types were mixed with binder using the ratio filler (soil type): binder-1:1.5, water: binder- 0.45 and cork sheet was also used $0.5 \%$ of binder (Figure 3 ). At the time of mixing, two-thirds of the required water was added within 1 minute and mixed for 2 minutes. Then, the remaining water was added and mixed for 1 minute. As soon as the mixing was finished, cement-soil mixtures were poured fully into a 50mm X 160mm X50 mm mould (Figure 4).

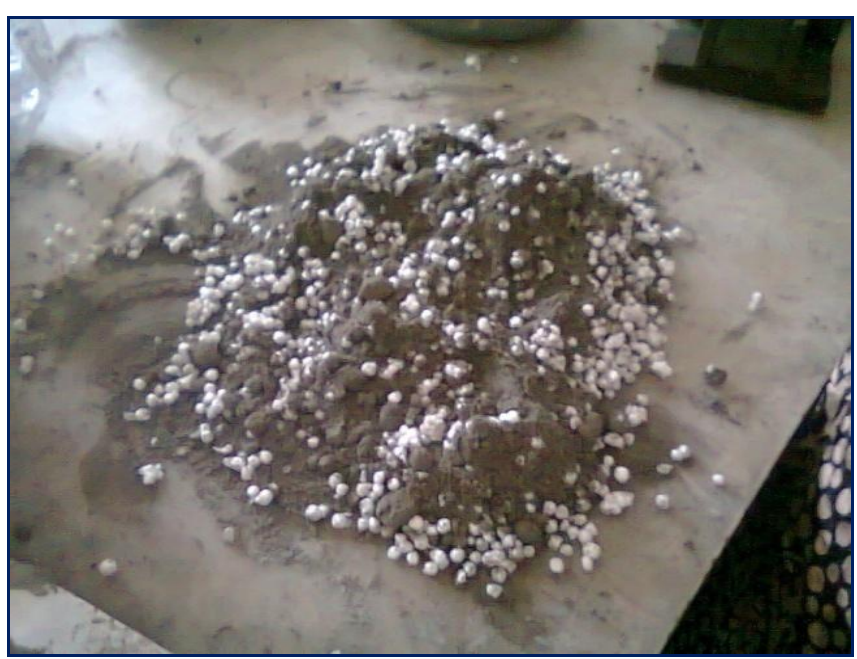

Figure 3 Mixing of the specimens

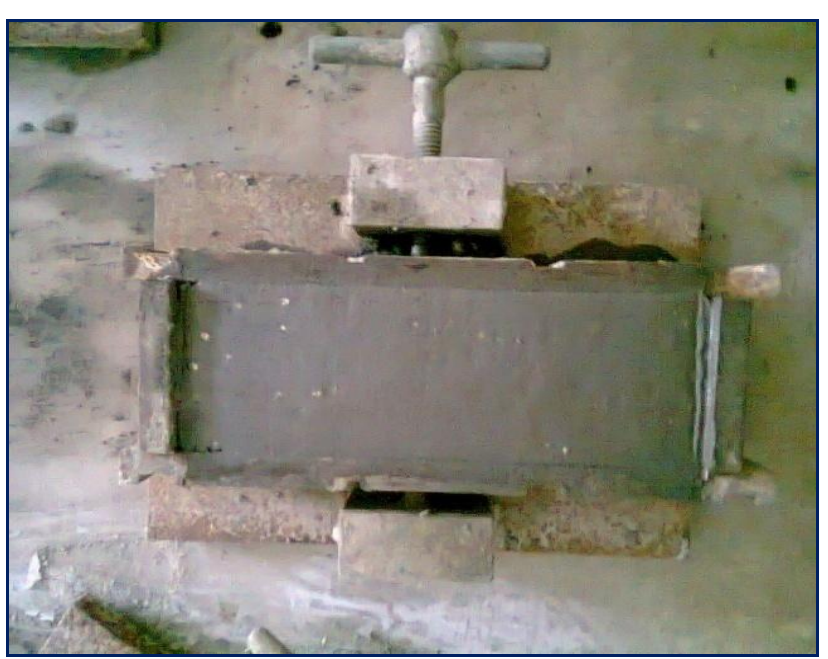

Figure 4 Casting of the specimens

Each soil type was compacted in three layers using the required number of blows. The specimens were kept at room temperature and demolded after 24 hours (Figure 5). After demolding the specimens were stored in water under curing ages of $1,3,7,14,28,56,112$ days. After curing the surface of the specimens were dried for some time. Then the specimens were taken to the Compression Testing Machine to measure compressive and flexural strength (Figure 6). 


\section{Journal of Civil Engineering, Science and Technology}

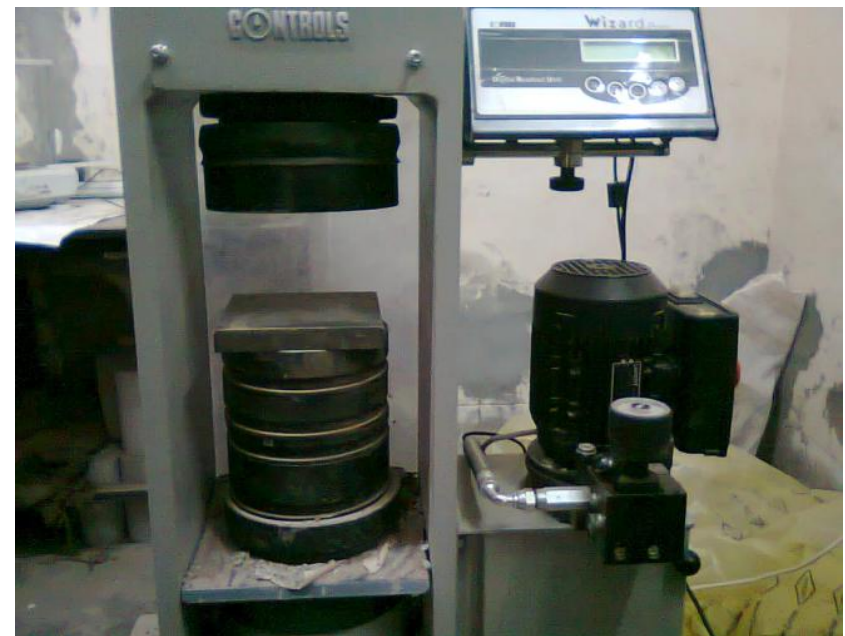

Figure 5 Specimens after demolding

Figure 6 Compression testing machine

\subsection{RESULTS AND ANALYSIS}

The presence of organic content in soil has a major effect on strength properties of cement-soil block. The variation of compressive strength with different organic content is shown in Figure 7. The graph shows the overall increase of compressive strength which is greatly influenced by organic content. The compressive strength for $20 \%$ organic content is maximum, after which strength decreases with increase in organic content. The graphical representation shows the scattering pattern of flexural strength which is greatly influenced by organic content. No definite relationship can be explained between flexural strength and organic content.
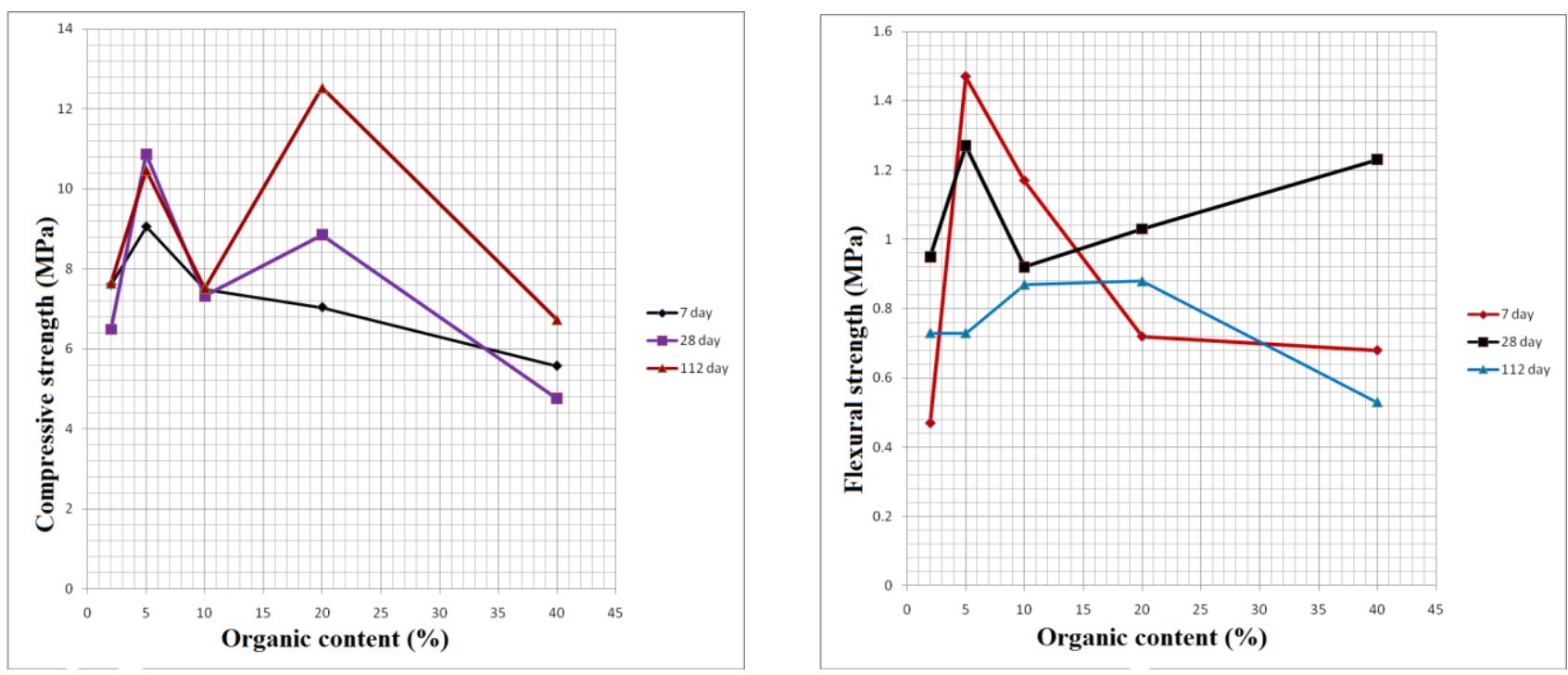

Figure 7 Variations of compressive strength and flexural strength with organic content.

The graphical representation shows the linear relationship of density with organic content. The density of cement-soil decreases with increase of organic content (Figure 8). Based on Figure 9, it is apparent the compressive strength increased with time or age in a curvilinear manner. This can be readily explained from the fact that the degree of cement hydration and amount of cement gel formed in the cement paste increase with age. The graph shows the overall increase of compressive strength. The compressive strength for $20 \%$ organic content is maximum, after which strength decreases with further curing age. 


\title{
Journal of Civil Engineering, Science and Technology
}

\author{
Volume 8, Issue 1, April 2017
}

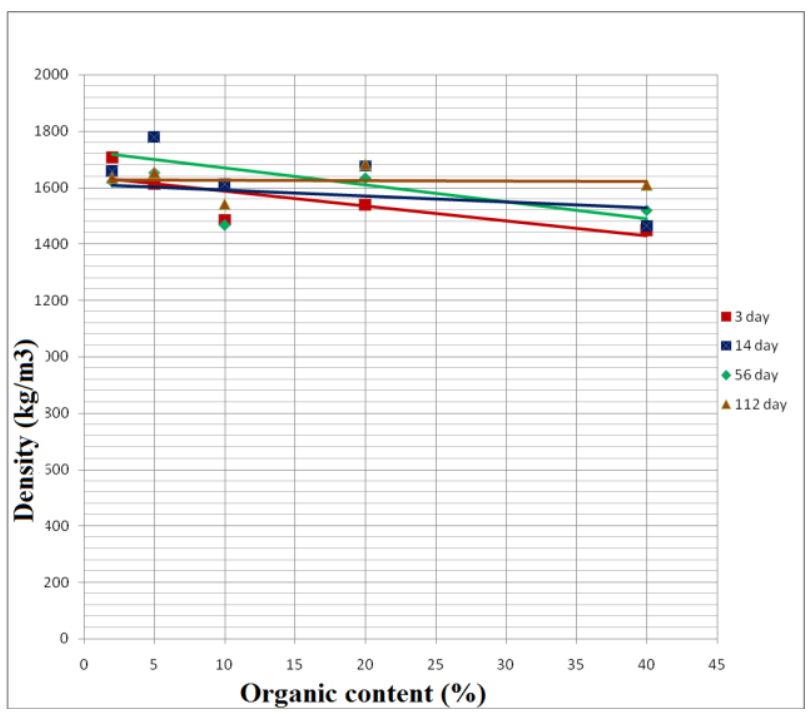

Figure 8 Variation of density with organic content.

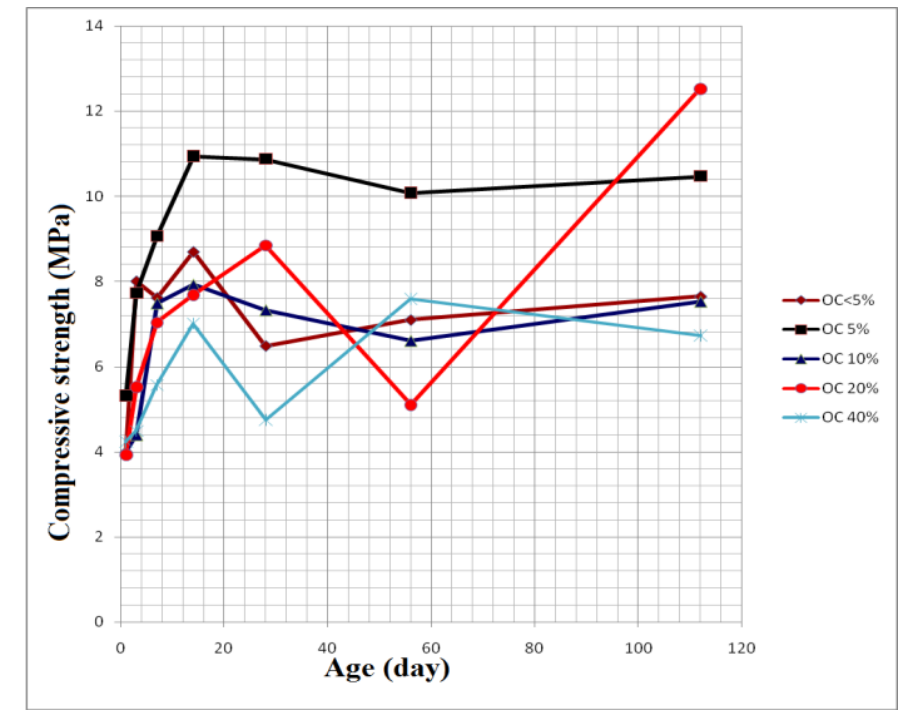

Figure 9 Variation of compressive strength with age

\subsection{CONCLUSIONS}

The density of organic soil based compressed cement-soil block decreases with increase of organic content. The compressive strength increases up to $20 \%$ organic content beyond which it decreases. No definite relationship can be drawn between flexural strength and organic content. The average ratio of compressive strength and flexural strength was 1.23 of compressed cement-soil block for $20 \%$ organic content. This investigation will play a vital role in selecting load bearing and non-load bearing applications. It is important and urgent to source for alternative materials to reduce the negative impact of developments towards the environment. This investigation has created a strong impetus to embark in using soil filler in compressed cement-soil block for non-load bearing applications. Further studies should consider replacing cork sheet with chemical aluminium powder or hydrogen peroxide powder as a foaming agent.. The strength determination in this work was done by center point loading system. The three point loading system is preferable for strength determination and recommended for future studies.

\section{REFERENCES}

[1] Anthony, G. K. (2001). Durability of compressed and cement-stabilized building blocks, PhD Thesis, University of Warwick, Coventry,England.

[2] Ahnberg, H. and Holm, G. (1999). "Stablisation of some Swedish organic soils with different types of binder." Proceeding of the International Conference on Dry Mix Method for Deep Soil Stabilisation, Stockholm, pp. 101-108.

[3] Ahnberg, H., Johansson, S. -E., Pihl, H., and Carlsson, T. (2003). "Stabilizing effects of different binders in some Swedish soils." Ground Improvement, Vol. 7, No. 1, pp. 9-23.

[4] Carter, M. and Bentley, S. P. (1991). Correlations of soil properties, Pentech Press, London, England.

[5] Das, B. M. (1983). Fundamentals of soil dynamics, Elsevier Science Publishing Co., New York, USA.

[6] Enteiche, A. (1964). Soil cement; Its use in Building, United Nations Publications, New York, USA

[7] Fitzmaurice, R. (1958). Manual on stabilized soil construction for housing, Technical Assistance Program, United Nations, New York.

[8] Hebib, S. and Farrell, E. (1999). "Some experience of stabilizing Irish organic soils." Proceeding of the International Conference on Dry Mix Method for Deep Soil Stabilization, Stockholm, pp. 81-84.

[9] Houben, H. and Guillaud, H. (1994). Earth construction: A comprehensive guide, IT Publication, London.

[10] Jimenez Delgado, M. C. and Guerrero, I. C. (2007). "The selection of soil for unstabilised earth building: A normal review." Construction and Building Materials, Vol. 21, No. 2, pp. 237-251.

[11] Mohamed, A. M. O. (2000). "The role of clay minerals in marly soil on its stability."Engineering Geology, Vol. 57, Issues 3-4, pp. 193-203. 


\title{
Journal of Civil Engineering, Science and Technology
}

\author{
Volume 8, Issue 1, April 2017
}

[12] Morel, J. C., Abalo Pkla, and Walker, P. (2007). "Compressive strength testing of compressed earth blocks." Construction and Building Materials, Vol. 21, No. 2, pp. 303-309.

[13] Walker, P. (1995). "Strength, durability and shrinkage characteristics of cement stabilized soil blocks." Cement and Concrete Composites, Vol. 17, No. 4, pp. 301-310.

[14] Walker, P. and Stace, T. (1997). "Properties of some cement stabilized compressed earth blocks and mortars." Materials and Structures, Vol. 30, November, pp. 545-551.

[15] Walker, P. J. (2004). "Strength and erosion characteristics of earth blocks and earth block masonry." Journal of Materials in Civil Engineering, ASCE, Vol. 16, No. 5, pp. 497-506.

[16] Venkatarama Reddy, B. V. and Gupta, A. (2005). "Characteristics of soil-cement blocks using highly sandy soils." Materials and Structures, Vol. 38, No. 6, pp. 651-658.

[17] Veith, G. (2000). "Green, ground and great: Soil stabilization with slag." Building Research \& Information, Vol. 28, No. 1 , pp. 70-72. 